\title{
Sexual activity and dyspareunia the first year postpartum in relation to degree of perineal trauma
}

Kathrine Fodstad $^{\mathrm{a}, \mathrm{b}}$, MD, Anne Cathrine Staff ${ }^{\mathrm{a}, \mathrm{b}}$, MD, PhD, Katariina Laine ${ }^{\mathrm{b}}$ MD, PhD

${ }^{a}$ Faculty of Medicine, University of Oslo, Norway

${ }^{\mathrm{b}}$ Department of Obstetrics and Gynaecology, Oslo University Hospital, Ullevål, Norway

\begin{abstract}
Introduction and Hypothesis Knowledge on sexual complaints and time to sexual resumption after obstetric anal sphincter injury (OASI) is scarce. The aim of the study was to investigate self-reported sexual activity and coital problems one year postpartum in relation to perineal trauma, as well as delivery mode. Methods Among 2846 women recruited during pregnancy, all women who delivered with OASI ( $n=42$, all $3^{\text {rd }}$ degree perineal tears), as well as 20 randomly selected controls per OASI case, in total 882 women, were sent a selfadministered questionnaire addressing time to coital resumption after delivery and potential coital difficulty one year postpartum. Results By 8 weeks, half of the 561 responders $(51.4 \%)$ had resumed intercourse, increasing to $75.2 \%$ by 12 weeks and $94.7 \%$ one year postpartum. In multivariate regression analysis OASI was the strongest predictor for postponed coital onset, defined as after 8 weeks (aOR 5.52, CI 1.59-19.16). OASI was also the only significant predictor for dyspareunia one year after delivery (aOR 3.57, CI 1.39-9.19). Episiotomy was neither a risk factor for postponed coital onset nor for dyspareunia. There were no differences between episiotomy and second degree laceration injury groups regarding postponed coital onset $(\mathrm{p}=0.45)$ or dyspareunia one year postpartum $(\mathrm{p}=0.67)$. Conclusions OASI was a strong and independent predictor for both postponed coital resumption after delivery and for dyspareunia one year postpartum, whereas episiotomy and spontaneous second degree lacerations were not. Our main finding of affected sexual activity after OASI further supports the need of reducing the rates of this obstetric injury to a minimum.
\end{abstract}

Keywords dyspareunia, episiotomy, obstetric anal sphincter injury, sexual activity

\section{Brief Summery}

Postponed resumption of intercourse after delivery, as well as dyspareunia one year postpartum was significantly associated with obstetric anal sphincter injury, but not with episiotomy.

\section{Introduction}

Obstetric anal sphincter injury

(OASI) is a serious complication of childbirth with potential long term maternal morbidity, such as anal incontinence and reduced quality of life. Perineal pain and dyspareunia appear to be related to the extent of perineal trauma [14]. However, very few studies have addressed sexual activity after OASI in a long-term prospective time span of more than six months [5-8]. In general, some studies assessing perineal pain and dyspareunia in relation to different degrees of perineal trauma (but not to OASI specifically) have methodological limitations, such as mixing heterogeneous degrees of perineal lacerations [5,9-13] or failing to specify degree of perineal trauma $[10,14,15]$. Systematic reviews are difficult to perform due to heterogeneous study design, heterogeneous evaluation of exposure and/or outcome measure as well as assessment at different postpartum intervals. Consequently, advising women who have suffered obstetric anal sphincter injury on potential future sexual functioning after delivery is equally difficult. 
The aim of the study was to investigate self-reported sexual activity and problems with intercourse one year after delivery in relation to perineal trauma, including OASI, as well as mode of delivery.

\section{Methods}

This study is part of the Perineum Study which was approved by the Regional Committee for Medical Research Ethics in South-Eastern Norway (ref. S08810d/20941).

Study population

The Perineum Study population initially consisted of 2846 pregnant women recruited prospectively during routine ultrasound examination in second trimester at Oslo University Hospital, Ullevål, from September 2009 to August 2010, as shown in the flowchart (Figure 1). This routine ultrasound examination is offered to all pregnant women in Norway in gestational week 18-20, and 98\% attend. Participants answered a questionnaire in Norwegian (Q1, Figure 1) concerning urinary and anal incontinence, general health condition and worries related to pregnancy and delivery. Demographic data, obstetrical history, educational level, household income, and country of origin were also collected. Results have been published previously [16]. All participants gave written informed consent, also agreeing to receive further questionnaires after the index delivery.

Of these 2846 participating pregnant women, 42 subsequently delivered with an obstetric anal sphincter injury (OASI, defined as perineal injury degree 3 or 4 ; however all OASI cases in our study were $3^{\text {rd }}$ degree tears). The OASI incidence rate of $1.5 \%$ in our study population is representative for the current low OASI incidence rate at Oslo University Hosptial, Ullevål. These 42 OASI women, together with 840 randomly selected controls (20 controls per case, selected from the initial study population of 2846) who delivered without OASI, were sent a structured questionnaire by postal mail one year after delivery. The questionnaire (Q2, Figure 1) addressed time of resumption of coitus after delivery, questions on whether there were current problems with intercourse after delivery and specification of such problems. Specifications were prelisted as 1) Pain at the vaginal orifice during penetration, 2) Pain during deep penetration, 3) Feeling of having too wide a vaginal introitus, 4)

Feeling of having too tight or sore a vaginal introitus, 5) Coital garulitas, 6) Anal incontinence, 7) Urinary incontinence, 8) Fear of incontinence of any kind, 9) Lack of sexual desire, 10) Self-reported written specification of any other type of problem. The questionnaire also addressed birth control use and breastfeeding in addition to potential worries concerning socioeconomic status or in regards to motherhood, family or partner relationships. Questions concerning these worries were chosen from the validated Cambridge Worry Scale [17], which was modified to address postpartum women who were not pregnant. The Q2 questionnaires were merged with data from the Oslo University Hospital local obstetrical database and with the first questionnaire during pregnancy (Q1).

\section{Definition of perineal trauma}

Perineal injury was classified following delivery and registered in the obstetrical database as degree 1 to 4 , according to international guidelines [18]. The Oslo University Hospitals local obstetrical database does not document the type of episiotomy performed. However, local guidelines at Oslo University hospital, Ullevål recommend the lateral episiotomy technique when episiotomy is clinically indicated. The lateral technique is defined as an incision commencing $\geq 10 \mathrm{~mm}$ from the posterior fourchette and directed towards the ischial tuberosity. Midline episiotomy technique is discouraged in this delivery unit. Mediolateral incisions are 
also commonly performed, second to the lateral episiotomies [18].

\section{Statistical analysis}

Chi square test was used in the univariate analysis, and a significance level of $5 \%$ was chosen. Univariate analysis was performed to identify the significant risk factors associated with resumption of sexual activity and with dyspareunia, and variables with $p<0.05$ were included in the multivariate analyses. Multivariate regression analysis was used to explore the adjusted OR for postponed onset of coitus (defined by us as more than 8 weeks postpartum) and self-reported dyspareunia, with 95\% confidence interval. Eight weeks was chosen as a cut-off as all women in Norway are encouraged to have a postpartum check-up approximately 6-7 weeks after delivery. We hypothesized that many women therefore might not resume coitus prior to such a clinical examination. Model 1 depicts maternal characteristics and delivery method solely. In model 2, delivery characteristics, such as duration of second stage of labor, epidural analgesia, persistent occiput posterior presentation, episiotomy and OASI were added. In model 3 we analyzed all degrees of perineal injury and episiotomy separately, and intact perineum was used as reference. PASW (Predictive Analytics SoftWare, SPSS Inc, Chicago, Illinois, USA) version 22 was used to perform the analyses.

\section{Results}

\section{Participants}

Of the 882 women (42 cases and 840 controls) recruited to this study, $64 \%$ $(n=561)$ responded and returned the questionnaire (Q2). Response rates were similar for the OASI cases (67\%) and the controls (64\%). Table 1 summarizes the clinical characteristics of respondents and non-respondents. Responders and nonresponders did not differ in age, parity, degree of perineal trauma or mode of delivery (Table 1). The majority of responders were primiparous (62\%), while
$30 \%$ of responders had given birth to their second child, and the remainders (8\%) were para 3 at the index delivery (Table 1).

Responder's birth outcomes

Most responders (69\%) had delivered spontaneously, $12 \%$ were delivered by vacuum extraction, $6 \%$ had a planned caesarean and $13 \%$ had an emergency cesarean section (Table 1). Seventeen women had a preterm delivery before 37 weeks and seven women delivered twins. Among the 561 responding women, 34\% $(\mathrm{n}=194)$ delivered with an intact perineum and $21 \%(n=120)$ underwent an episiotomy only, whereas the remaining group had some degree of perineal tear: $32 \%(n=177)$ sustained a $1^{\text {st }}$ degree perineal tear, $8 \%$ $(n=42)$ a second degree tear while $5 \%$ $(n=28)$ sustained a third degree tear. Of the 28 OASI cases, 9 were peroperatively classified 3A, 19 were classified 3B and none were of degree $3 \mathrm{C}$ or 4 (data not shown).

Resumption of sexual activity postpartum By 8 weeks about half of the responders (51.4\%) had resumed coitus, and by 12 weeks $75.2 \%$ had resumed intercourse, whereas $94.7 \%$ had resumed coitus one year postpartum. Six women (1.1\%) reported attempted coitus, but had interrupted their attempt, and 23 women (4\%) had not yet attempted coitus. Two respondents did not answer this particular question and one woman had listed "other" as her answer.

Table 2 shows resumption of coitus categorized by 8 weeks, by 9-12 weeks and after 3 months in relation to degree of perineal trauma and method of birth, showing a significant difference related to degree of perineal trauma. Women with OASI were significantly more likely to postpone coitus till after three months compared to any of the groups of women with less severe degree of perineal trauma or episiotomy, $\mathrm{p}<0.05$. When comparing second degree tears to episiotomy per se, we found no significant difference in 
percentage distribution of coital resumption between these two groups at the three time points studied (data not shown, $\mathrm{p}=0.84$ ). Women with lower educational level were significantly more likely to postpone coital resumption till after 3 months postpartum as compared to women with college and university education (Table 2, $\mathrm{p}<0.05$ ). We found no significant difference in percentage distribution of coital resumption when comparing different delivery modes. Neither was there a significant difference in percentage distribution in relation to parity or breastfeeding (Table 2).

Univariate logistic regression analysis is presented in Table 3 and shows that OASI increased the risk of postponed onset of coitus (defined as after 8 weeks) by a sevenfold $(\mathrm{OR}=6.97$, Table 3$)$ compared to intact perineum.

Multivariate regression analyses for all variables significantly associated with postponed onset of coitus in the univariate regression analysis are also presented in Table 3. Parity was also included, despite not representing a significant risk for postponed sexual intercourse in the crude analyses, as we considered parity a potentially important confounding factor in our study of events associated to labor and delivery. In model 1 parity and maternal age were associated with postponed sexual resumption after delivery, maternal age only slightly associated with an aOR 1.09.

In model 2 maternal age and OASI were the only significant risk predictors for postponed onset of sexual resumption (aOR 1.10 and 4.16). In contrast, episiotomy was no longer significantly associated with postponed resumption of coitus in these adjusted analyses, despite being a significant risk in the unadjusted analysis.

In model 3, as in model 2, maternal age remained statistically significant, but a minor risk factor for postponed sexual resumption (aOR 1.10), and OASI remained again the only strong and statistically significant predictor for postponed resumption of intercourse after delivery (aOR 5.52). Other degrees of perineal trauma were not significantly associated with postponed resumption of coitus (Table 3, model 3).

The models 2 and 3 were also performed after excluding all women who delivered by cesarean section, but this did not change the conclusions (data not shown). We additionally compared women with an episiotomy $(n=120)$ to women with a second degree perineal laceration $(n=42)$ separately in a multivariate analysis, and there was no difference between these two groups in relation to postponed resumption of coitus ( $p=0.42$, data not shown).

In addition to the presented variables above, we analyzed a large number of maternal, fetal and obstetrical variables to assess if other factors could contribute to the postponed sexual resumption 8 weeks after delivery. Maternal body mass index (BMI), breastfeeding and vaginal delivery route compared to caesarean were not associated with timing of sexual resumption, neither were obstetrical interventions such as labor induction, epidural use or oxytocin augmentation. Newborn characteristics, such as large baby (birth weight, head circumference), gestational age (prematurity), twins or low Apgar scores, were not associated with postponed onset of sexual activity after birth (data not shown).

Women who reported to not have resumed coitus by 12 months, were asked to state the reason for non-resumption. Seven of these 23 women reported they were not in a relationship. Ten women (44\%) reported the reason to be lack of sexual desire (two were OASI deliveries, two had delivered with an intact perineum, three with a first degree tear, one with a second degree tear and two with an episiotomy only). Two women stated the reason for non-resumption to be that they were afraid of coital pain (of which one had a spontaneous second degree tear while the other had delivered with a first 
degree perineal tear only). The remainder four women did not give a reason for nonresumption.

\section{Difficulty with coitus/Dyspareunia one year postpartum}

The majority of participants (545 of 561) stated they were currently in a relationship at one year postpartum, whereas 19 women stated they were not and 6 women did not answer this particular question. When asked whether currently experiencing difficulty with coitus after delivery, 530 of 561 women responded, of which 164 reported to have current coital problems, while 366 women stated to have none. At one year postpartum, significantly more women with OASI reported "having difficulties with coitus" as compared to any other group of women with perineal trauma (48\% versus $22 \%$ for second degree tears, 32\% for episiotomy, and 37\% for first degree perineal tears, $\mathrm{p}<0.02$ ) and as compared to women with intact perineum $(23 \%, \mathrm{p}<0.02)$.

Participants were asked to specify their difficulty, either by choosing from a predefined list and/or give their own written specification of the problem. None of the responders provided a written specification. The most frequently reported problem was lack of sexual desire (63.4\%), followed by dyspareunia, defined as either pain at the vaginal orifice during penetration (41.5\%) or pain during deep penetration (37.2\%). Forty-seven women (28.7\%) specified that the vaginal orifice felt too tight or sore during coitus, while 27 participants (16.5\%) considered the vaginal orifice as being too large. Very few reported to have incontinence issues, only five women listed urinary incontinence as their coital difficulty, 12 women reported flatus incontinence, but none reported fecal incontinence. However, 17 women (10.4\%) stated their problem to be fear of incontinence of any type.

Table 4 shows dyspareunia types one year postpartum by degree of perineal trauma and mode of delivery. Women with
OASI were significantly more likely to experience pain at the vaginal orifice during coitus compared to women without OASI (39\% vs. 6-19\%, p<0.05, Table 4). We also found a borderline significance concerning pain at the vaginal orifice when comparing vacuum deliveries to spontaneous and cesarean deliveries, $\mathrm{p}=0.07$, but when comparing vaginal deliveries to cesareans per se, there was no significant difference between groups, $\mathrm{p}=0.41$ (data not shown).

With respect to deep penetrational pain, there was no significant difference between different degrees of perineal trauma, although the group of women with vacuum deliveries had significantly higher rate of such pain than other delivery groups $(\mathrm{p}<0.05$, Table 4).

Crude and adjusted logistic regression analyses of the 102 women reporting dyspareunia is presented in Table 5. The crude analysis showed that OASI significantly increased the risk of dyspareunia by a four-fold compared to intact perineum (OR 4.00). Maternal BMI, household income, educational level, delivery mode and breastfeeding were not significantly associated with dyspareunia one year after birth. Neither were fetal variables like birthweight, head circumference, gestational age (prematurity), twins, occiput posterior presentation, shoulder dystocia or Apgar scores (data not shown).

In multivariate regression analysis of all factors associated with dyspareunia, worries concerning relations to friends and family were significantly associated with dyspareunia (Table 5, model 1 ). In model 2 , OASI (all were third degree perineal tears) remained the only significant as well as a strong predictor for dyspareunia (aOR 2.98). In model 3 OASI remained again the only significant predictor for dyspareunia (aOR 3.57). None of the other degrees of perineal trauma were significantly associated with dyspareunia (Table 5, model 3), despite episiotomy being a 
significant risk in the non-adjusted analyses.

When separately comparing women with episiotomy to women with second degree laceration in multivariate regression analysis, there was no significant difference between these two groups in regards to dyspareunia, $\mathrm{p}=0.67$ (data not shown).

\section{Discussion}

Our study showed that women with OASI had an increased risk of postponed onset of coitus (defined as after 8 weeks) by a fourto fivefold as well as having significantly increased risk for dyspareunia by a three-to fourfold at one year after delivery, assessed in two different multivariate analyses models (model 2 and 3, Tables 3 and 5).

This is the first study to assess both time of resumption of coitus as well as dyspareunia one year postpartum in relation to OASI and mode of delivery adjusted for potential confounding factors in multivariate analyses. We demonstrated that OASI increased the risk of postponed onset of coitus by a fivefold compared to intact perineum, and that a significantly larger proportion of women with OASI postponed resumption of intercourse till after 3 months as compared to all other degrees of perineal trauma. A postponed resumption of coitus after OASI is in compliance with findings from previous studies from Sweden and the United States $[3,8]$. Rådestad et al found that adjusted relative risks for not having had sexual intercourse within 3 and 6 months were 2.1 and 2.2 for tears in the sphincter ani and rectum. Similar to the study by Rådestad et al, our question concerning time to coital resumption was retrospective, with the possibility of a recollection bias. Had we sent questionnaires addressing the same issues at several occasions postpartum, the response rates would most likely have decreased throughout a one year follow-up period. Hence, we might have lost valuable one year postpartum data. We also recognize that time of resumption of coitus after delivery may not only be influenced by obstetric factors or the great variety of individual aspects, but also by cultural variations and attitude towards female sexuality after childbirth. In Norway, all women with vaginal delivery are encouraged to have a postpartum gynecological examination approximately 6-7 weeks postpartum. Many Norwegian women may therefore not resume (or consider resuming) intercourse before having had such a check-up, which is supported by our finding that only half of our responders reported to be sexually active 8 weeks after delivery. Consequently, we chose to dichotomize resumption of coitus to 8 weeks in our logistic regression analyses.

We did not find episiotomy to be a risk factor for postponed onset of coitus (defined as after 8 weeks) in multivariate analysis, nor did we find a second degree spontaneous perineal laceration to be associated with postponed onset of coitus. When categorizing coital resumption into three groups (by 8 weeks, by 3 months and after 3 months) there were no significant differences between episiotomy and second degree tears in percentage distribution of time to coital resumption. This is an interesting finding as results from previous studies generally differ in regards to coital resumption and dyspareunia comparing episiotomy to spontaneous perineal lacerations [2,3,810,13,19-21]. The differing results might be explained by studies grouping mixed degrees of perineal trauma into one single group [9-13,19,21,22]. A strength in our study is the separate categorization of all degrees of perineal trauma as well as separately studying episiotomy and spontaneous second degree tears. Another advantage of our study in terms of securing accuracy is that the recorded delivery data on perineal trauma in the local obstetrical database was checked up against individual medical charts (considered gold standard) of all the 561 responding women by the first and last author. 
A noteworthy finding is the quite large proportion of woman with intact perineum and first degree tears (19\% in both groups) reporting postponed onset of coitus till after 3 months. A plausible explanation for this finding might be sexual habits and complaints prior to pregnancy and delivery, on which we have no information. We cannot exclude an inclusion bias, as women experiencing coital difficulty or women having more worries about resumption of coitus after childbirth may be more prone to answer a sexual activity questionnaire compared to women who do not experience such problems. On the other hand, our finding of OASI being the only significant as well as a major risk factor for postponed resumption is in concordance with existing literature.

\section{Difficulty with coitus/dyspareunia the first} year after delivery

OASI increased the risk of dyspareunia one year postpartum by three-to fourfold in our multivariate regression analyses. In contrast, other degrees of perineal trauma, episiotomy included, were not independently associated with dyspareunia one year postpartum in our adjusted analyses.

Long-term follow up studies of more than 6 months after childbirth in relation to dyspareunia or sexual functioning are rare, and even fewer address OASI in particular. Our finding of OASI being the biggest risk factor for dyspareunia one year after delivery is in slight contrast to an Australian study of 440 primigravida women. The authors found that at 12 months postpartum sexual function had returned to early pregnancy levels, irrespective of mode of delivery or degree of perineal injury [23]. The OASI group, in this study was very small $(\mathrm{n}=9)$, and therefore the conclusions may have limited value. A weakness of our study is that we did not address sexual satisfaction, and we recognize that dyspareunia in itself is not a measure of female sexual dissatisfaction.

Ejegård et al found that episiotomy, second degree perineal lacerations, and a history of dyspareunia were independent risk factors for dyspareunia 12-18 months postpartum [19]. In our study neither episiotomy, nor second degree lacerations were risk factors for dyspareunia 12 months postpartum compared to intact perineum, which again is in compliance with the findings of de Souza et al [23]. What strengthens our findings is that we have analyzed all obstetric factors associated with dyspareunia in a multivariate regression, which Ejegård et al did not [19].

A limitation to our study is that we lack information on potential coital difficulties prior to pregnancy and delivery. We have however no reason to believe that our OASI population would differ in terms of dyspareunia or other sexual problems prior to delivery as compared with our control group.

Van Brummen et al showed that primiparous women were five times less likely to be sexually active one year postpartum after a third/fourth degree tear as compared to women with an intact perineum [5]. The majority of our OASI population was however sexually active one year after delivery, but none had sustained a $4^{\text {th }}$ degree perineal injury, in accordance with the currently very low rate of the most severe OASI form in our delivery unit. Whether or not our nonresponding OASI women were sexually active, is unknown to us, and again, we cannot exclude an inclusion bias even though our responders and non-responders did not differ in regards to age, degree of perineal trauma, mode of delivery or parity.

We did not use a validated questionnaire in our study, as our aim was not to assess detailed female sexual function, merely to address potential sexual problems such as dyspareunia one year postpartum. The Norwegian Institute 
of Public Health has conducted several epidemiological survey studies on health and sexual behavior in Norway using unvalidated questionnaires, but used, similarly to us, simple questions like "are you sexually active or not", with the response options being “yes" and "no”. If the answer was "yes", the degree of sexual problems were measured by the question "Have you experienced any of the sexual problems listed below during the past 12 months/or since sexual activity was retained after birth” [24]. We therefore considered our simple questions about coital difficulties one year after delivery to be appropriate to assess our outcome measure of interest.

Despite potential redundant confounding factors, like individual differences in sexual activity and other non-registered variables of importance, our persistent and clear study finding is that OASI remains a large risk factor for postponed resumption of sexual intercourse after delivery as well as for dyspareunia one year postpartum. Our study is not a randomized controlled trial comparing episiotomy use and risk of OASI, but we found no support neither for episiotomy being a risk for postponed sexual intercourse, nor for episiotomy being a risk factor for dyspareunia one year postpartum. And importantly, we found no difference in coital resumption when comparing episiotomy to second degree lacerations separately. And even though episiotomy should only be used on indication, and not routinely, we advocate that episiotomy should be used when indicated to reduce the risk of OASI. Our previous studies have documented that a reduction in OASI rates is possible, also without a large increase in episiotomy rates $[25,26]$. Our main finding of affected sexual activity after OASI strongly supports the need of reducing the rates of this obstetric injury to a minimum.
Acknowledgements All participating women are greatly acknowledged for their willingness, and for taking time, to answer the questionnaire.

Funding The University of Oslo provided funding for a PhD student grant (KF).

\section{References}

(1) Abdool Z, Thakar R, Sultan AH (2009) Postpartum female sexual function. Eur J Obstet Gynecol Reprod Biol 145:133-137.

(2) Andrews V, Thakar R, Sultan AH, Jones PW (2008) Evaluation of postpartum perineal pain and dyspareunia--a prospective study. Eur J Obstet Gynecol Reprod Biol 137:152-156.

(3) Signorello LB, Harlow BL, Chekos AK, Repke JT (2001) Postpartum sexual functioning and its relationship to perineal trauma: a retrospective cohort study of primiparous women. Am J Obstet Gynecol 184:881-8; discussion 888-90.

(4) Andreucci CB, Bussadori JC, Pacagnella RC et al (2015) Sexual life and dysfunction after maternal morbidity: a systematic review. BMC Pregnancy Childbirth 15:307-0150742-6.

(5) van Brummen HJ, Bruinse HW, van de Pol G, Heintz AP, van der Vaart CH (2006) Which factors determine the sexual function 1 year after childbirth? BJOG 113:914-918.

(6) Mous M, Muller SA, de Leeuw JW (2008) Long-term effects of anal sphincter rupture during vaginal delivery: faecal incontinence and sexual complaints. BJOG 115:234238.

(7) Otero M, Boulvain M, BianchiDemicheli F et al (2006) Women's health 18 years after rupture of the anal sphincter during childbirth: II. Urinary incontinence, sexual function, and physical and mental health. Am J Obstet Gynecol 194:1260-1265. 
(8) Rådestad I, Olsson A, Nissen E, Rubertsson C (2008) Tears in the vagina, perineum, sphincter ani, and rectum and first sexual intercourse after childbirth: a nationwide followup. Birth 35:98-106.

(9) Larsson PG, Platz-Christensen JJ, Bergman B, Wallstersson G (1991) Advantage or disadvantage of episiotomy compared with spontaneous perineal laceration. Gynecol Obstet Invest 31:213-216.

(10) Buhling KJ, Schmidt S, Robinson JN, Klapp C, Siebert G, Dudenhausen JW (2006) Rate of dyspareunia after delivery in primiparae according to mode of delivery. Eur J Obstet Gynecol Reprod Biol 124:42-46.

(11) Leeman LM, Rogers RG, Greulich B, Albers LL (2007) Do unsutured second-degree perineal lacerations affect postpartum functional outcomes? J Am Board Fam Med 20:451-457.

(12) Rogers RG, Borders N, Leeman LM, Albers LL (2009) Does spontaneous genital tract trauma impact postpartum sexual function? J Midwifery Womens Health 54:98-103.

(13) Sleep J, Grant A, Garcia J, Elbourne D, Spencer J, Chalmers I (1984) West Berkshire perineal management trial. Br Med J (Clin Res Ed) 289:587-590.

(14) McDonald EA, Gartland D, Small R, Brown SJ (2015) Dyspareunia and childbirth: a prospective cohort study. BJOG 122:672-679.

(15) McDonald EA, Brown SJ (2013) Does method of birth make a difference to when women resume sex after childbirth? BJOG 120:823-830.

(16) Laine K, Skjeldestad FE, Sandvik L, Staff AC (2013) Prevalence and Risk Indicators for Anal Incontinence among Pregnant Women. ISRN Obstet Gynecol 2013:947572.

(17) Green JM, Kafetsios K, Statham HE, Snowdon CM (2003) Factor structure, validity and reliability of the Cambridge Worry Scale in a pregnant population. J Health Psychol 8:753764.

(18) Sultan AH, Thakar R, Fenner D (2007) Perineal and anal sphincter trauma. : Springer London.

(19) Ejegard H, Ryding EL, Sjogren B (2008) Sexuality after Delivery with Episiotomy: A Long-Term Follow-Up. Gynecol Obstet Invest 66:1-7.

(20) Klein MC, Gauthier RJ, Robbins JM et al (1994) Relationship of episiotomy to perineal trauma and morbidity, sexual dysfunction, and pelvic floor relaxation. Am J Obstet Gynecol 171:591-598.

(21) Chang SR, Chen KH, Lin HH, Chao YM, Lai YH (2011) Comparison of the effects of episiotomy and no episiotomy on pain, urinary incontinence, and sexual function 3 months postpartum: a prospective follow-up study. Int J Nurs Stud 48:409-418.

(22) Robson KM, Brant HA, Kumar R (1981) Maternal sexuality during first pregnancy and after childbirth. Br J Obstet Gynaecol 88:882-889.

(23) De Souza A, Dwyer P, Charity M, Thomas E, Ferreira C, Schierlitz L (2015) The effects of mode delivery on postpartum sexual function: a prospective study. BJOG 122:14101418.

(24) Traeen B, Stigum H (2010) Sexual problems in 18-67-year-old Norwegians. Scand J Public Health 38:445-456.

(25) Laine K, Rotvold W, Staff AC (2012) Are obstetric anal sphincter ruptures preventable?- Large and consistent rupture rate variations between the Nordic countries and between delivery units in Norway. Acta Obstet Gynecol Scand 92:94-100.

(26) Laine K, Skjeldestad FE, Sandvik L, Staff AC (2012) Incidence of obstetric anal sphincter injuries after training to protect the perineum: cohort study. BMJ Open 2:10.1136/bmjopen-2012001649. Print 2012. 
Figure 1 Flowchart demonstrating the selection of the study cases (OASI: women with obstetric anal sphincter injury) and controls.

Invitation letter to participate in the Perineum study ( $n=7256$, sent together with the appointment for routine ultrasound week 17-19 at the Hospital) September 2009-August 2010.

Spontaneous abortion prior to US week 17-19 or delivered in another hospital or moved out of Norway $(n=973)$

Eligible population for The Perineum Study

Questionnaire 1 (Q1) (n=6283)

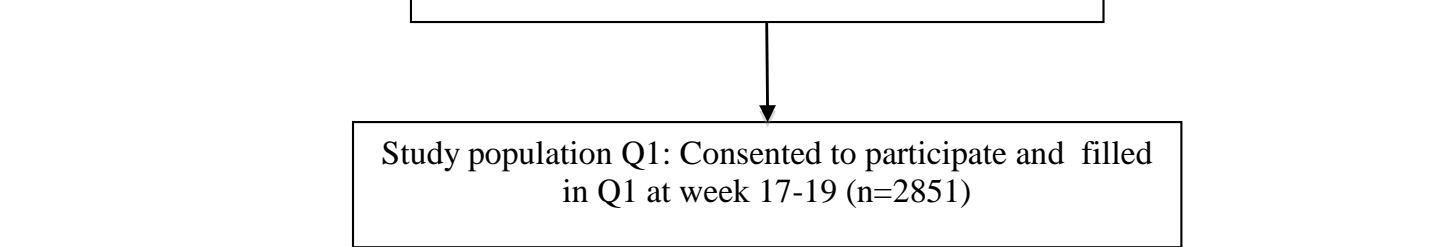

Returned Q1 twice $(n=4)$
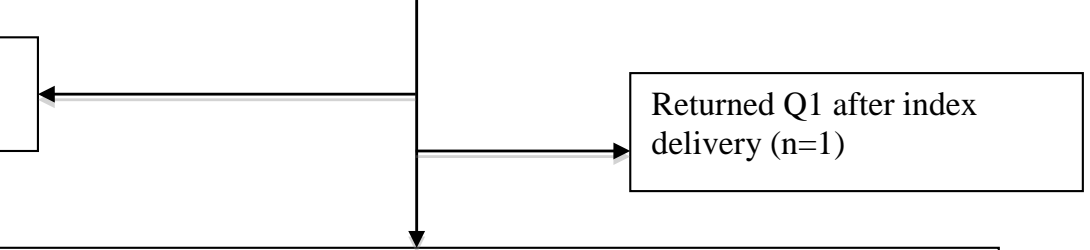

Delivery in 2010-11

Eligible for the current Perineum Study Questionnaire 2 study (n=2846)

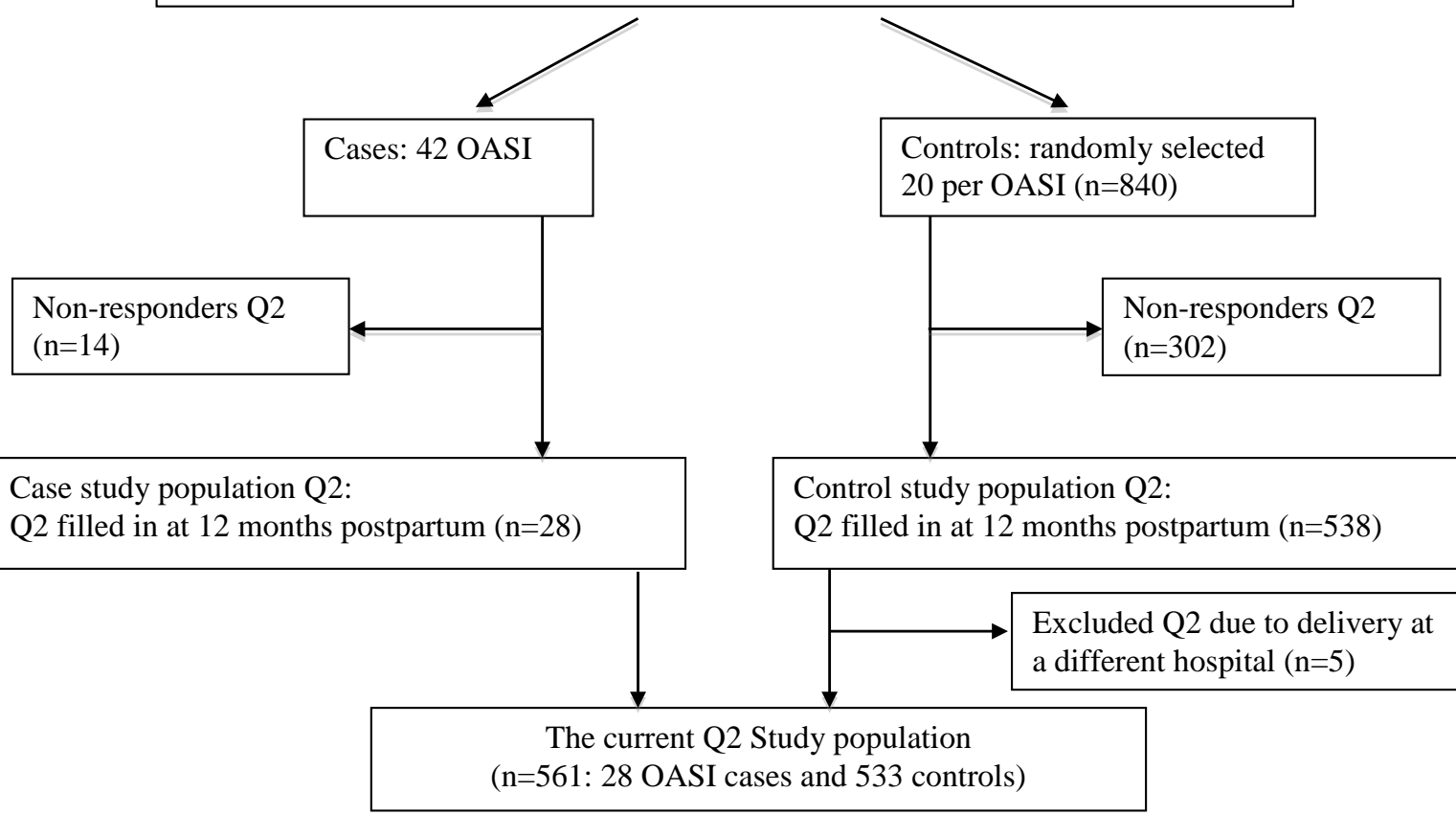


Table 1 Clinical characteristics of invited study participants, n=877 ( 5 of 882 women were excluded due to delivery at a different hospital) displayed for responders and non-responders. Values are given in percentage distribution (and number). OASI: obstetric anal sphincter injury.

\begin{tabular}{|c|c|c|c|}
\hline & $\begin{array}{c}\text { Responders } \\
n=561\end{array}$ & $\begin{array}{c}\text { Non-responders } \\
n=316\end{array}$ & $\mathbf{p}^{*}$ \\
\hline Age (mean) & 31.7 & 31.0 & 0.09 \\
\hline Age categorized & $\%$ (n) & $\%$ (n) & 0.08 \\
\hline $18-29$ & $36(166)$ & 30 (115) & \\
\hline $30-35$ & $48(286)$ & $51(151)$ & \\
\hline $36-44$ & 16 (109) & $19(49)$ & \\
\hline Parity & $\%(n)$ & $\%(n)$ & 0.92 \\
\hline Primiparous & 62 (349) & 61 (193) & \\
\hline Para 2 & 30 (166) & $30(95)$ & \\
\hline Para 3 & $8(46)$ & $9(28)$ & \\
\hline Mode of delivery & $\%(n)$ & $\%(n)$ & 0.11 \\
\hline Spontaneous & 69 (387) & 66 (209) & \\
\hline Vacuum extraction & $12(68)$ & $15(46)$ & \\
\hline Forceps & $0(0)$ & $2(5)$ & \\
\hline Planned cesarean & $6(34)$ & $8(26)$ & \\
\hline Emergency cesarean & $13(72)$ & $9(30)$ & \\
\hline Perineal trauma & $\%(n)$ & $\%$ (n) & 0.77 \\
\hline Intact perineum & 34 (194) & 34 (106) & \\
\hline $1^{\text {st }}$ degree perineal tear & 32 (177) & $29(92)$ & \\
\hline $2^{\text {nd }}$ degree tear & $8(42)$ & $8(26)$ & \\
\hline $3^{\text {rd }}$ degree tear (OASI) & $5(28)$ & $4(14)$ & \\
\hline Episiotomy & $21(120)$ & $25(78)$ & \\
\hline
\end{tabular}

* Chi-squared test and ANOVA 
Table 2 Resumption of coitus in relation to method of birth, perineal trauma and (answered by 502 of 561 study responders). Values are given in percentage (and numbers). For some women, information on income and educational level was lacking. OASI: obstetric anal sphincter injury.

\begin{tabular}{|c|c|c|c|c|c|}
\hline & \multirow{2}{*}{$\begin{array}{c}\begin{array}{c}\text { Total } \\
(\mathbf{n}=502)\end{array} \\
\mathbf{n}\end{array}$} & \multicolumn{4}{|c|}{$\begin{array}{c}\text { Resumed coitus postpartum } \\
\text { \% (n) }\end{array}$} \\
\hline & & $\begin{array}{c}\text { Within } 8 \\
\text { weeks } \\
(n=258)\end{array}$ & $\begin{array}{c}\text { 9-12 } \\
\text { weeks } \\
(n=120) \\
\end{array}$ & $\begin{array}{c}\text { After } 12 \\
\text { weeks } \\
(n=124) \\
\end{array}$ & $\mathbf{p}^{*}$ \\
\hline Delivery method & & & & & 0.11 \\
\hline Spontaneous vaginal birth & 351 & $52(183)$ & $25(88)$ & $23(80)$ & \\
\hline Vacuum extraction & 62 & $37(23)$ & $24(15)$ & $39(24)$ & \\
\hline Planned cesarean section & 26 & $58(15)$ & $23(6)$ & $19(5)$ & \\
\hline Emergency cesarean section & 63 & $59(37)$ & $17(11)$ & $24(15)$ & \\
\hline Perineal trauma & & & & & $<0.05$ \\
\hline Intact perineum & 170 & 58 (99) & 23 (39) & $19(32)$ & \\
\hline $1^{\text {st }}$ degree perineal tear & 163 & $59(96)$ & $22(36)$ & $19(31)$ & \\
\hline $2^{\text {nd }}$ degree tear & 39 & $46(18)$ & $23(9)$ & $31(12)$ & \\
\hline OASI ( $3^{\text {rd }}$ degree tear) & 24 & $17(4)$ & $33(8)$ & $50(12)$ & \\
\hline Episiotomy & 106 & $39(41)$ & $26(28)$ & 35 (37) & \\
\hline Intact perineum & & & & & 0.19 \\
\hline Vaginal delivery & 82 & $57(47)$ & $28(23)$ & $15(12)$ & \\
\hline Cesarean section & 88 & $59(52)$ & $18(16)$ & $23(20)$ & \\
\hline Parity & & & & & 0.52 \\
\hline Vaginal primiparous & 309 & $50(154)$ & $26(79)$ & $25(76)$ & \\
\hline Multiparous & 193 & $54(104)$ & $21(41)$ & $25(48)$ & \\
\hline Breastfeeding & & & & & 0.83 \\
\hline Yes & 92 & $51(47)$ & $26(24)$ & $23(21)$ & \\
\hline No & 409 & $51(210)$ & $24(96)$ & 25 (103) & \\
\hline Marital status & & & & & 0.78 \\
\hline Married & 282 & $31(88)$ & $45(126)$ & $24(68)$ & \\
\hline Co-habitant & 209 & $29(61)$ & $46(96)$ & $35(52)$ & \\
\hline Single & 11 & $36(4)$ & $27(3)$ & 25 (124) & \\
\hline Educational level (n=499) & & & & & $<0.05$ \\
\hline Primary School/High School & 83 & $22(18)$ & $36(30)$ & $42(35)$ & \\
\hline$\leq 4$ years of College & 192 & $38(72)$ & $44(85)$ & $18(35)$ & \\
\hline$\geq 5$ years University & 224 & $28(62)$ & 48 (108) & $24(54)$ & \\
\hline Household Income ${ }^{1}(n=484)$ & & & & & 0.13 \\
\hline Below 500000 NOK & 90 & $27(24)$ & $39(35)$ & $34(31)$ & \\
\hline 5-700 000 NOK & 67 & $34(23)$ & $52(35)$ & $13(9)$ & \\
\hline 7- $900000 \mathrm{NOK}$ & 146 & $32(47)$ & $43(63)$ & $25(36)$ & \\
\hline$>9000000 \mathrm{NOK}$ & 181 & $32(58)$ & $45(82)$ & $23(41)$ & \\
\hline
\end{tabular}

* Chi squared test

${ }^{1}$ Values are given in Norwegian Krones (NOK). 500.000 NOK equals 57.350 US dollars, 700.000NOK equals 80.290 US dollars and 900.000 NOK equals 103.230 US dollars 
Table 3. Crude and adjusted OR for postponed sexual resumption (defined as after 8 weeks, $n=244$ ) after the index delivery. OASI: obstetric anal sphincter injury.

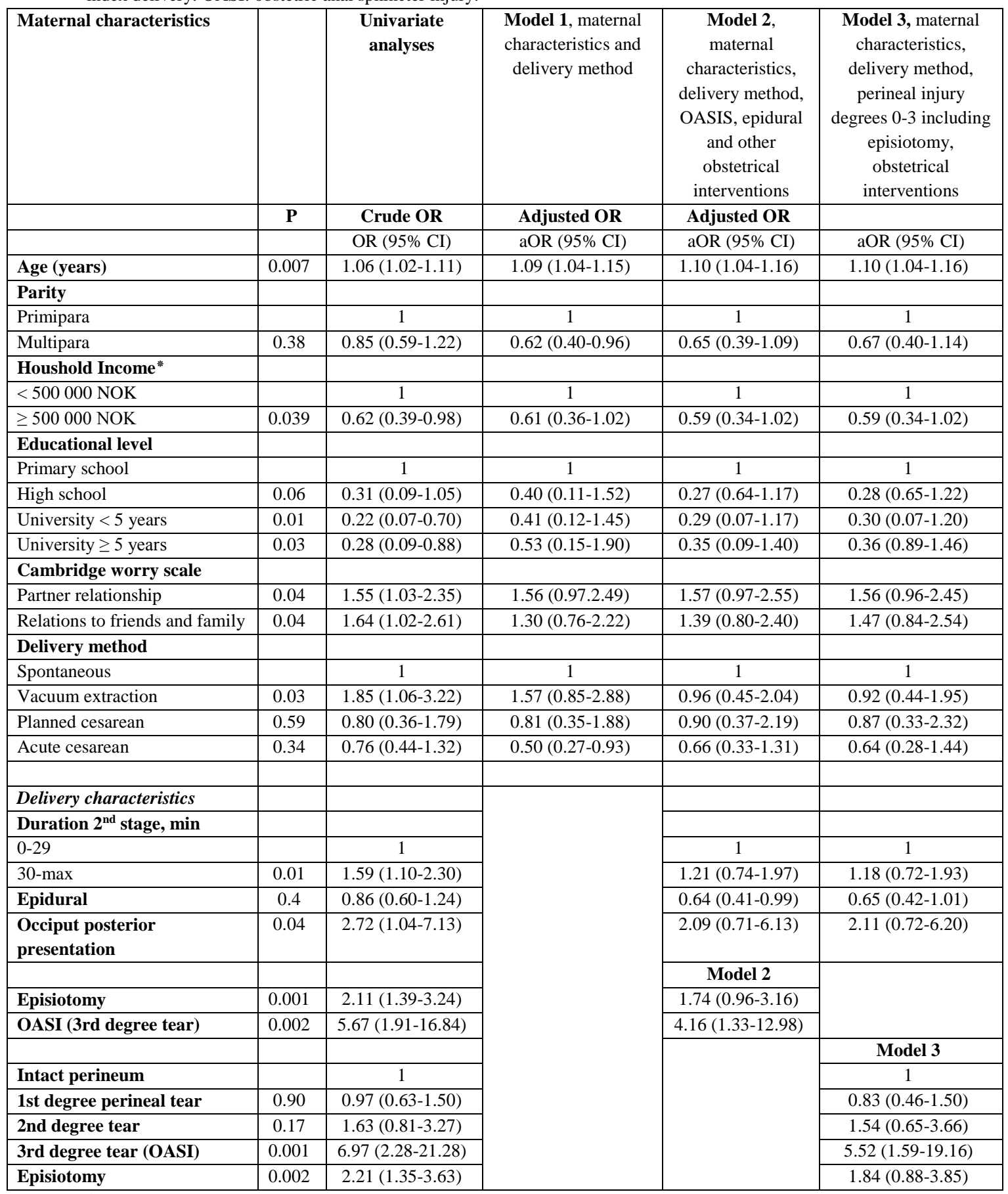

${ }^{*}$ Household Income is given in Norwegian Kroner (NOK). 500.000 NOK equals 57.350 US dollars 
Table 4 Self-reported types of dyspareunia one year postpartum in relation to degree of perineal trauma and mode of delivery. Values are given in percentages (and numbers). OASI: obstetric anal sphincter injury.

\begin{tabular}{|c|c|c|c|c|c|c|c|}
\hline & $\begin{array}{c}\text { Total } \\
(n=561)\end{array}$ & 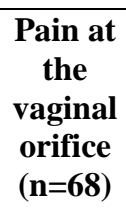 & $\begin{array}{l}\text { No pain } \\
(n=493)\end{array}$ & $\mathbf{p}$ & $\begin{array}{c}\text { Deep } \\
\text { penetrational } \\
\text { pain } \\
(n=61)\end{array}$ & $\begin{array}{l}\text { No pain } \\
(n=500)\end{array}$ & $\mathbf{p}$ \\
\hline Perineal trauma & & $\%(n)$ & $\%(n)$ & $<0.05$ & $\%(n)$ & $\%(n)$ & 0.32 \\
\hline Intact perineum & 194 & $6(12)$ & 94 (182) & & $11(21)$ & 89 (173) & \\
\hline $\begin{array}{l}1^{\text {st }} \text { degree } \\
\text { perineal tear }\end{array}$ & 177 & $10(18)$ & 90 (159) & & $8(14)$ & 92 (163) & \\
\hline $2^{\text {nd }}$ degree tear & 42 & $10(4)$ & 90 (38) & & $10(4)$ & $90(163)$ & \\
\hline $\begin{array}{l}\text { OASI } \\
\left(3^{\text {rd }} \text { degree tear }\right)\end{array}$ & 28 & $39(11)$ & $61(17)$ & & $11(3)$ & $89(25)$ & \\
\hline Episiotomy & 120 & $19(23)$ & 81 (97) & & $84(101)$ & $16(19)$ & \\
\hline Method of birth & & $\%(n)$ & $\%$ (n) & 0.07 & $\%(n)$ & $\%(n)$ & $<0.05$ \\
\hline $\begin{array}{l}\text { Spontaneous } \\
\text { vaginal birth }\end{array}$ & 383 & $11(43)$ & 89 (340) & & $9(34)$ & 91 (349) & \\
\hline $\begin{array}{l}\text { Vacuum } \\
\text { extraction }\end{array}$ & 71 & $21(15)$ & $79(56)$ & & $20(14)$ & $80(57)$ & \\
\hline $\begin{array}{l}\text { Planned cesarean } \\
\text { section }\end{array}$ & 34 & $6(2)$ & $94(32)$ & & $3(1)$ & 97 (33) & \\
\hline $\begin{array}{l}\text { Emergency } \\
\text { cesarean section }\end{array}$ & 73 & $11(8)$ & $89(65)$ & & $16(12)$ & $84(61)$ & \\
\hline
\end{tabular}


Table 5. Crude and adjusted OR for self-reported dyspareunia one year after the index delivery $(\mathrm{n}=102)$. OASI: obstetric anal sphincter injury.

\begin{tabular}{|c|c|c|c|c|c|}
\hline $\begin{array}{l}\text { Maternal } \\
\text { characteristics }\end{array}$ & & $\begin{array}{l}\text { Univariate } \\
\text { analyses }\end{array}$ & $\begin{array}{c}\text { Model 1, } \\
\text { maternal } \\
\text { characteristics }\end{array}$ & $\begin{array}{c}\text { Model 2, } \\
\text { maternal } \\
\text { characteristics, } \\
\text { delivery method, } \\
\text { OASIS, epidural } \\
\text { and other } \\
\text { obstetrical } \\
\text { interventions }\end{array}$ & $\begin{array}{c}\text { Model 3, } \\
\text { maternal } \\
\text { characteristics, } \\
\text { delivery method, } \\
\text { perineal injury } \\
\text { degrees } 0-3 \\
\text { including } \\
\text { episiotomy, } \\
\text { obstetrical } \\
\text { interventions }\end{array}$ \\
\hline & $\mathbf{P}$ & Crude OR & Adjusted OR & Adjusted OR & Adjusted OR \\
\hline & & OR (95\% CI) & aOR (95\% CI) & aOR (95\% CI) & aOR (95\% CI) \\
\hline Age (years) & 0.14 & $0.96(0.91-1.01)$ & $1.00(0.94-1.06)$ & $1.01(0.95-1.07)$ & $1.01(0.95-1.07)$ \\
\hline \multicolumn{6}{|l|}{ Parity } \\
\hline Primipara & & 1 & 1 & 1 & 1 \\
\hline Multipara & 0.016 & $0.56(0.35-0.90)$ & $0.64(0.38-1.09)$ & $0.85(0.48-1.51)$ & $0.86(0.48-1.55)$ \\
\hline \multicolumn{6}{|l|}{$\begin{array}{l}\text { Cambridge worry } \\
\text { scale }\end{array}$} \\
\hline Partner relationship & 0.03 & $1.66(1.04-2.64)$ & $1.42(0.85-2.39)$ & $1.45(0.85-2.47)$ & $1.46(0.86-2.48)$ \\
\hline $\begin{array}{l}\text { Relations to friends } \\
\text { and family }\end{array}$ & 0.003 & $2.11(1.29-3.46)$ & $1.77(1.00-3.14)$ & $1.64(0.91-2.95)$ & $1.73(0.96-3.12)$ \\
\hline Working situation & 0.05 & $1.56(1.00-2.42)$ & $1.32(0.82-2.12)$ & $1.33(0.82-2.16)$ & $1.33(0.82-2.17)$ \\
\hline Drinking & 0.025 & 3.45 (1.17-10.17) & $2.55(0.82-7.94)$ & $2.42(0.72-8.15)$ & $2.26(0.67-7.61)$ \\
\hline \multicolumn{6}{|l|}{$\begin{array}{l}\text { Delivery } \\
\text { characteristics }\end{array}$} \\
\hline $\begin{array}{l}\text { Duration stage 1, } \\
\text { hours }\end{array}$ & 0.068 & $1.06(1.00-1.13)$ & & $1.00(0.92-1.09)$ & $1.01(0.93-1.10)$ \\
\hline \multicolumn{6}{|l|}{$\begin{array}{l}\text { Duration } 2^{\text {nd }} \text { stage, } \\
\text { minutes }\end{array}$} \\
\hline $0-29$ & & 1 & & 1 & 1 \\
\hline 30-max & 0.05 & $1.54(1.00-2.38)$ & & $1.26(0.73-2.19)$ & $1.27(0.72-2.24)$ \\
\hline \multirow[t]{2}{*}{ Epidural } & 0.04 & $1.57(1.02-2.42)$ & & $1.26(0.74-2.43)$ & $1.31(0.77-2.24)$ \\
\hline & & & & Model 2 & \\
\hline Episiotomy & 0.006 & $1.92(1.21-3.07)$ & & $1.39(0.79-2.43)$ & \\
\hline \multirow[t]{2}{*}{ OASI (3rd degree ) } & 0.005 & 3.14 (1.43-6.93) & & $2.98(1.28-6.91)$ & \\
\hline & & & & & Model 3 \\
\hline Intact perineum & & 1 & & & 1 \\
\hline 1st degree tear & 0.61 & $1.16(0.66-2.06)$ & & & $0.94(0.49-1.81)$ \\
\hline 2nd degree tear & 0.40 & $1.46(0.61-3.48)$ & & & $1.43(0.56-3.68)$ \\
\hline 3rd degree tear & 0.002 & $4.00(1.69-9.46)$ & & & 3.57 (1.39-9.19) \\
\hline Episiotomy & 1.88 & (1.05-3.39) & & & $1.24(0.60-2.58)$ \\
\hline
\end{tabular}

